\title{
Cultura y política: relaciones e implicaciones. Un análisis en clave de ciudadanía
}

\author{
Claudia Kuzma Zavaleta \\ Trabajadora social \\ Montevideo, Uruguay
}

\section{Resumen}

El interés de este artículo es el análisis de los conceptos de cultura y política, así como el de su dimensión cultural con respecto a la sociedad y la participación ciudadana en este proceso.

Palabras claves: cultura y política, ciudadanía, América Latina, identidad cultural

\begin{abstract}
The interest of this article is to analize the concepts of culture and politics, as well as their cultural dimension in relation to society and the participation of citizens in this process.
\end{abstract}

Keywords: culture and politics, citizenship, Latin America, cultural identity

\section{A modo de introducción}

$\Delta$ lo largo del presente artículo se procura analizar desde una mirada compleja dos dimensiones que han estado históricamente entrelazadas: la "cultura" y la "política" El objetivo principal de este ejercicio teórico es aportar a la reflexión en torno a la importancia de la dimensión cultural en relación con la construcción de sociedades inclusivas, justas y democráticas. Dicha construcción requiere de "actores sociales" creativos, capaces de tomar decisiones, con participación activa en la elaboración de un proyecto colectivo; en una palabra: de "ciudadanos"1

1 El concepto de "ciudadanía" elaborado por el sociólogo británico T.H. Marshall estaba compuesto de tres elementos: a) El elemento civil, o sea aquellos derechos necesarios para gozar de libertad individual (libertad de expresión, de pensamiento, de religión, el derecho a la propiedad, a establecer contratos válidos y el derecho a la justicia). b) El elemento político, es decir, el derecho a participar en el ejercicio del poder político como miembros de un cuerpo con autoridad política, o como elector de sus miembros. Las 
El concepto de "ciudadanía" ha sido objeto de numerosos estudios y discusiones en los últimos tiempos, dado que parecería haberse vaciado de contenido, y con ello el de democracia ha perdido su significado, reducido a la legalidad. Sin duda, este vaciamiento se relaciona con esta "globalización" de perfil neoliberal y sus consecuencias políticas no sólo en América Latina sino en el mundo entero. Podría decirse que la "ciudadanía" como concepto y como práctica se encuentra en crisis, y ello si bien genera preocupación y desorientación entre intelectuales y políticos, también representa un desafío provocador y la oportunidad para repensar qué modelo de sociedad queremos. En este sentido, algunos autores que cuestionan fuertemente el sentido y contenido del concepto "ciudadano", plantean la necesidad de volver al "sujeto" concreto, real, con necesidades y demandas (Acosta, 2005).

instituciones vinculadas a este elemento son -entre otras-el parlamento y las juntas del gobierno local. c) EI elemento social, el cual abarca desde el derecho a la seguridad y a un mínimo bienestar económico, hasta el de compartir la herencia social y vivir la vida de un ser "civilizado", según los estándares de la sociedad. Las instituciones relacionadas con dicho elemento son fundamentalmente el sistema educativo y los servicios sociales. Hasta aquí el concepto de Marshall.

Ahora bien, la "ciudadanía" no es una realidad dada, sino conquistada desde la lucha de los sujetos. Es un concepto determinado por su contexto social, político, económico y cultural; por tanto en permanente evolución. Por ello en la actualidad se plantea incorporar, además, los llamados "derechos culturales" dentro de esta noción.

Por su parte C. Coutinho (1997) plantea que la “ciudadanía” es la “...capacidad conquistada por algunos individuos o por todos los individuos que se apropian de los bienes socialmente creados, que realizan todas sus potencialidades abiertas por la vida social en cada contexto históricamente determinado". Soberanía popular, democracia y ciudadanía constituyen la misma cosa. Coutinho.
Democracia y ciudadanía son dos realidades que reclaman ser resignifícadas desde la dialéctica entre lo "instituyente" y lo “instituido". La democracia consiste en un sistema jurídico-político de organización de la vida colectiva, que necesita de la participación de todos, ya sea directamente o a partir de mecanismos de representación.

La "ciudadanía" posee dos niveles: jurídico-político, que se expresa en instancias de participación directa o representativa, de carácter universalista no excluyente; y económico-social, que refiere a las condiciones materiales que dan la posibilidad de vivir, también de carácter universalista no excluyente. Sin la articulación de estos dos niveles no existe ciudadanía democrática, ni orden democrático. La ciudadanía económico-social sin ciudadanía jurídico-política “es ciega" y la ciudadanía jurídico-política sin ciudadanía económico-social "es vacía” (Kant, 1781).

Por lo tanto, ambas realidades requieren de la participación de todos, sin exclusión. Pero ello no es posible sin sujetos activos, sin actores sociales, lo cual implica un aprendizaje y procesos de "empoderamiento", donde entra en juego el mundo simbólico-cultural, que propicien la acción política no sólo desde instancias formales, sino en la vida cotidiana, entendiendo la política desde un sentido amplio pero no abstracto, como "el arte de lo posible" (tanto nacional como local).

La discusión y el debate sobre esta relación "cultura" y "política" adquiere gran relevancia en el actual momento histórico de nuestro continente, donde las dimensiones de la pobreza y la desigualdad 
social -que se profundizan aún más entre las comunidades indígenas y negras- son cada vez más escandalosas. Pero también donde parecería que las manifestaciones de resistencia y de visibilidad del problema étnico y de las "identidades culturales" en relación con el sistema político y económico han cobrado mayor fuerza, con la aparición de los "nuevos actores sociales": los movimientos sociales ("el neozapatismo" de Chiapas, el movimiento indígena ecuatoriano, las fuerzas sociales del nuevo gobierno en Bolivia, etc.). Se trata de un momento histórico donde la problemática de la pluriculturalidad, la multiculturalidad y las identidades ha adquirido protagonismo en el contexto de la "globalización cultural” (Giddens, 2001).

Con el objetivo de aportar a estos debates y reflexiones, se considera necesario presentar un breve recorrido histórico por las distintas formas de abordaje de "la cultura" que, como todo el conocimiento, es construida y determinada por su contexto social, político y económico. Dicho recorrido permite visualizar cómo las distintas corrientes teóricas que sustentan dicha noción constituyen un producto cultural creado desde los centros de estudios e investigadores latinoamericanos. Y cómo dichas corrientes han ido transformándose al ritmo de los cambios generados en la sociedad.

Esta revisión y replanteamiento sobre el abordaje de "la cultura" dentro de la antropología, a partir de la introducción de nuevos paradigmas pero también de determinados procesos políticos en América Latina, permite plantear un enfoque interdisciplinario (o transdisciplinario) y pensar sobre sus incumbencias histórico- políticas. Dentro de esta nueva visión de la "cultura," surge el interés por abordar las denominadas "identidades culturales", su potencialidad teórica y sus implicaciones en la búsqueda de una nueva política y una nueva ciudadanía, por tanto de un Estado plural y una sociedad inclusiva.

Finalmente, se presenta una serie de reflexiones y comentarios finales que pretenden abrir el debate así como plantear una serie de líneas o tendencias para la investigación sobre el tema. No constituyen elaboraciones acabadas, sino primeras aproximaciones a una temática que despierta interés académico en la medida en que contribuya a alcanzar la "utopía" de un nuevo orden social liberador, donde todos puedan reconocerse como ciudadanos, por tanto como sujetos capaces de decidir sobre sí mismos y sobre su comunidad.

\section{El abordaje de "la cultura" en América Latina: del eurocentrismo" a las nuevas incumbencias histórico-políticas}

En esta tierra mulata, de africano y español, Santa Bárbara de un lado, del otro lado, Changó (N. Guillén).

El abordaje de la cultura como objeto de estudio desde la academia latinoamericana estuvo signado por las ideologías dominantes procedentes de Europa, como el "evolucionismo primario" desde finales del siglo XIX. Luego, a principios del siglo XX la influencia proviene desde los Estados Unidos, sobre todo a partir de la Segunda Guerra Mundial (Rodríguez, 1991). Por ello, los estudios reflejaban fuertes prejuicios hacia las tradiciones o costumbres de los pueblos y comunidades 
de América Latina. Pero, además, se tomaba como referencia la información procedente de las crónicas del siglo XVI. Estas reflejaban claramente los intereses económicos y políticos que sustentaron ideológicamente el posterior proceso de colonización iniciado en el siglo XVIII.

Estas contribuciones constituyeron, posteriormente, el discurso etnográfico $\mathrm{y}$ seudoantropológico, cuyo énfasis estaba puesto en la búsqueda del "origen de la nacionalidad", en la valorización de costumbres ancestrales de etnias indígenas y grupos campesinos y en encontrar explicaciones al mestizaje en la zona del Caribe (de origen africano).

Cabe destacar que en el caso de las comunidades negras si bien no existió un interés tan acentuado como con los indígenas por parte de la ciencia y del Estado, sí existieron otras formas del conocimiento como el arte (por ejemplo, la pintura y la literatura) que abordaron su temática. Se trata del "negrismo" (Schwartz, 1993): movimiento estético que surge en Europa basado en la búsqueda del exotismo y la plástica de los fetiches africanos, que es continuado como manifestación literaria. Se trata de un discurso plástico producido por una élite artística blanca y europea que incorpora la temática negra para divulgarla entre un público también blanco, del mismo grupo de élite cultural. Hay una descripción del negro por lo que tiene de exótico, de sensual y de "primitivo". Este movimiento de carácter "eurocentrista" es retomado por escritores latinoamericanos desde otro enfoque: "poesía afrocubana", "poesía afroantillana", "poesía negra", "poesía negroide", etc. En todo caso, son los europeos quienes llevan a los escritores latinoamericanos a reconocer la existencia del negro en países con herencia africana como las Antillas, Brasil, Cuba y Uruguay.

A diferencia de dicho movimiento estético, nace en América Latina por la década del treinta -especialmente en Brasil y Cubala "negritud". Se trata de un movimiento de concientización que busca reivindicar los derechos de los negros, preservar su "identidad" a través de su historia, de carácter acentuadamente político. En Brasil, la fundación del Partido Comunista en 1925 contribuyó a la formación de clase de los negros. En Cuba, con influencia de estas ideas surge un movimiento intelectual que posibilita el abandono del concepto de "raza" y el surgimiento del concepto de "cultura cubana", en la cual el negro pasa a ser considerado miembro de una clase social. Dentro de este movimiento se destacan el antropólogo y jurista Femando Ortiz y el periodista Nicolás Guillén.

Lo cierto es que, salvo algunas excepciones, la forma de abordar la realidad cultural en América Latina responde en gran medida al "nuevo orden económico mundial" surgido desde fines del siglo XIX. Es decir, paralelamente a la conformación de los Estados Nacionales latinoamericanos y a la estructura social heredada de la época de la colonización, se van imponiendo modelos económicos de dependencia que les permitiría a las sociedades dominantes europeas (y posteriormente a Estados Unidos) su gran crecimiento económico.

Desde la "antropología" se ejecutaba un plan sobre áreas o territorios estratégicos: el "área andina" y el "área Caribe" con dos 
vertientes que se iban a conformar en las disciplinas de mayor desarrollo teóricopráctico de la antropología neopositivista como ciencia social: la arqueología y la etnología, enfocadas ahora hacia la investigación, conocimiento y explicación de múltiples comunidades indígenas de la antigüedad prehispánica, y hacia sus nuevas manifestaciones contemporáneas como sociedades campesinas en el medio rural de la región.

Las primeras búsquedas y reflexiones fuertemente racionalizadas y utilitarias permitirían actuar en forma orgánica hacia la totalidad del sistema social y sus instituciones, bajo una lógica inseparable del desarrollo capitalista.

Más avanzado el siglo $\mathrm{XX}$, el conocimiento sobre las culturas de los pueblos latinoamericanos comenzó a suscitar la necesidad de incorporar a la sociedad nacional a vastos sectores de la población. Por ejemplo en México, donde los objetivos políticos de los regímenes posteriores a la Revolución implicaban poner el acento en la definición de una "identidad" que diera sustento ideológico a los propósitos de renovación inspirados en la "igualdad" y "participación" en la sociedad nacional para todos los grupos sociales, incluidos campesinos y etnias indígenas.

Los estudios en América Latina contaban con el apoyo de instituciones norteamericanas y europeas, aplicaban sobre todo la arqueología y el manejo de una concepción boasiana de "cultura como totalidad", y construían cronologías para dar idea sobre la distribución espacial de los grupos estudiados. Todo este esfuerzo aportaba poco a la explicación de la complejidad de las relaciones $\mathbf{y}$ procesos sobre la realidad de las sociedades históricas anteriores aztecas, mexicas, náhuatl, mayas y otros grupos- que habían ocupado extensas regiones en México y América Central, así como de las comunidades establecidas antes de la colonización en áreas del Caribe.

Estos proyectos se concretan en instituciones académicas donde sus resultados se manipulan ideológicamente con fines políticos de tipo populista. Así por ejemplo, en México se crea la Escuela Nacional de Antropología e Historia en 1937, donde la formación académica con fines nacionales se basaba en proyectos arqueológicos, etnográficos y etnológicos. Otros proyectos similares se llevan a cabo en Brasil, Perú y Venezuela.

En este período se destacan las investigaciones de J. Steward sobre comunidades agrarias, especialmente indígenas. A partir de sus aportes y de otros investigadores, los análisis se dirigen a comparar culturas diferentes para conformar estrategias de control y manipulación del "cambio cultural", sobre todo de sociedades agrarias, alteradas por el desarrollo capitalista y sus proyectos de industrialización, los cuales requerían incorporar a las comunidades indígenas como fuerza de trabajo a cambio de un salario. Además, se elaboran registros de sociedades agrarias diferentes, particularmente indígenas, para una “comprensión" más detallada; así como comparaciones sobre algunos aspectos de la cultura, las formas de vida y los perfiles generalizados sobre rasgos sociales aparentes de comunidades que seguían mostrando rechazo a la homogeneización 
capitalista, acaecida con el desarrollo de nuevas formas de explotación en el medio agrario y campesino.

A partir de 1941, aparecerá una cierta "ideología oficial" según la cual se buscaba integrar a las comunidades indígenas mediante la aceptación por parte de estas de los logros del mundo desarrollado- a las sociedades nacionales. Surge el llamado "indigenismo" como un instrumento "teórico-político" con el cual cada régimen nacional debería armar su acción frente al denominado "problema indígena". El "indigenismo" era una síntesis de los dictámenes establecidos desde centros académicos de Europa y los Estados Unidos y reconocía que las sociedades evolucionaban, a través de la historia, hacia formas "más elevadas" de desarrollo social que las acercaban a los "fines naturales" de la especie humana. Pero este desarrollo tenía un "carácter relativo", distintos niveles, por lo cual las comunidades indígenas merecían "respeto y consideración" por parte de quienes realizaban políticas sobre su destino como sociedades. Se establecían ciertos mecanismos apropiados en cada Estado Nacional para adoptar medidas respecto a estas comunidades -particularmente respecto a las etnias indígenas- que no atentaran contra sus patrimonios "económicos" o de sobrevivencia, contra sus estructuras sociales y organizaciones, sus formas de vida, sus sistemas de creencias, etc.

A partir de este año, se establece un acuerdo suscrito por todos los gobiernos donde se fijaban los lineamientos de una "sana política", se normaban los mecanismos para la consulta de casos y se obligaba a cada país a crear instituciones dirigidas a asumir estos acuerdos, en los cuales entra la responsabilidad de los Estados sobre comunidades indígenas que estuvieran en su territorio.

En la década del 50, la producción de conocimientos y reflexiones respecto a las comunidades estaban influenciados por el funcionalismo y el relativismo cultural, así como por el indigenismo en tanto ideología para la integración, donde se establecía la noción de "aculturación" en las explicaciones sobre los procesos históricos que mostraban los grupos sociales, como consecuencia de prácticas neocolonizadoras impuestas por las sociedades nacionales y sus aparatos de poder político y económico.

La formación de los antropólogos en las escuelas sólo servía para colaborar con los proyectos de "aculturación planeada" contra las formas de existencia y modos de vida de comunidades de indígenas y campesinas en general. Por esto, el discurso elaborado sobre dichas comunidades contenía justificaciones y racionalizaciones basadas en concepciones ideológicas prejuiciadas por un esencialismo inmanente que sustentaron múltiples proyectos, convirtiendo así a esos profesionales en "intelectuales orgánicos de la clase en el poder” (Guerrero, en Díaz Polanco y otros, 1989).

Este breve recorrido permite constatar formas de abordaje de la "cultura" donde se ha manipulado, controlado y ocultado la verdadera problemática del indígena. Es a partir de los 60 que este modelo de análisis entra en un proceso de ruptura, como consecuencia de procesos de independencia y liberación nacional en Asia, en Africa y 
en América -el caso de Cuba-. Surge la crítica a determinados paradigmas dominantes en las disciplinas y se reevalúan sus proposiciones en función del desarrollo económico, social, político y cultural que se vivía en las sociedades sometidas a sus análisis. Toda esta revisión permitió que tanto la antropología como la sociología se comenzaran a separar de las limitaciones ideológicas y teóricas, y buscaran nuevos enfoques en la comprensión de nuestras realidades latinoamericanas. La obra del brasileño Darcy Ribeiro es de gran significación para el proceso señalado, ya que a partir de una revisión crítica de algunos de los postulados evolucionistas llegaría a plantear una vuelta a enfoques neoevolucionistas más totalizadores, al considerar diversos aspectos sintetizados en las nociones de "proceso civilizatorio" y "revolución tecnológica".

Poco a poco, los antropólogos y demás cientistas sociales latinoamericanos comienzan a darse cuenta de que las prácticas "científicas" propuestas desde los centros hegemónicos de EE.UU. no permitían superar la dependencia científica, tecnológica y cultural. Dicha dependencia comienza a superarse ideológicamente a partir de procesos críticos que comenzaban a gestarse en el seno de algunos grupos de investigadores de América Latina.

Hacia mediados de la década de los 70 , se produce una ruptura decisiva con las concepciones neopositivistas manejadas en el campo de la arqueología y se introducen categorías del "materialismo histórico". A la vez, surgen congresos y reuniones de nivel regional por parte de académicos, que permitieron conformar una conciencia particular sobre las realidades sociales comunes, no sólo en la investigación sino también en la lucha ideológica y política de sus respectivos países. Desde estas instancias se promueve el reconocimiento de la arqueología social como la disciplina antropológica que ha marcado los desarrollos de mayor alcance y profundidad teórica para el análisis y comprensión de nuestras sociedades.

Los trabajos y aportes de L. Felipe Bate, Luis Lumbreras, M. Sanoja, Iraida Vargas, entre otros, ban enriquecido el debate y han ampliado el horizonte de la antropología, así como han promovido una visión crítica de los estudios antropológicos. Así, en los últimos años se ha producido una serie de reflexiones y análisis sobre problemas como la "manipulación política del pasado histórico" y del "patrimonio histórico-cultural de los pueblos", sobre las estrategias concientizadoras de nivel popular a partir de los museos y la divulgación de textos en la educación formal, en los cuales se trasmitía una concepción clasista y hegemónica, practicada por cierto tipo de historiadores, por algunos antropólogos culturales y amigos del "folklore". Dichas estrategias, con base en proyectos políticos orientados a la "homogeneización social", han pretendido borrar las diferencias entre culturas dentro de los países para facilitar la imposición de la lógica del "progreso y el desarrollo" de los sectores dominantes.

Dentro de esta línea de investigaciones interesa resaltar la noción de "cultura" que propone L. Felipe Bate (1978) -contraria a la tradición científica de la antropología burguesa $-y$ desde un enfoque 
materialista histórico. La noción de cultura en sus primeras aplicaciones había buscado explicar las apariencias fenoménicas de las sociedades diferentes, convirtiéndose así en un concepto cada vez más vacío de contenido.

Por el contrario, la noción de cultura ${ }^{2}$ de Bate permite explicar los nexos objetivos que ella presenta en cada sociedad con los contenidos más generales de los procesos que la expresan históricamente. También facilita diseñar los instrumentos metodológicos que permitan explicar esos procesos. De esta manera, se trata de una construcción teórica que muestra la relación entre cultura y formación económico-social. La otra noción vinculada a la de "cultura" que adquiere cada vez mayor relevancia y se va transformando a lo largo del tiempo es la de "identidad", ya que las tendencias neopositivistas de abordar el tema no logran dar cuenta de determinados procesos sociopolíticos en diversos contextos latinoamericanos, como los movimientos de liberación, las luchas armadas con participación de indígenas, la presencia de movimientos de carácter étnico en demandas socio-económicas de las sociedades nacionales en Bolivia, Perú y en América Central. Estos procesos reclaman un tratamiento desde la dimensión histórica del problema de la "identidad"

2 Según L. Felipe Bate la categoría de “cultura” supone... "el conjunto de formas singulares que presentan los fenómenos correspondientes al enfrentamiento de una sociedad a condiciones específicas en la solución histórica de sus problemas de desarrollo. Estos problemas generales de desarrollo, propios de la formación económico-social, constituyen el contenido fundamental a que corresponden las formas culturales. (en Rodríguez, 1991). por parte de las ciencias sociales ${ }^{3}$. A partir de la década de los 90, se replantea la problemática desde un enfoque teórico político, se generan nuevos ámbitos y dimensiones para el debate ideológico, permitiendo así ubicar la reflexión en un contexto que tradicionalmente había quedado excluido: las sociedades nacionales de América Latina.

En este contexto, se produce una dura crítica al llamado "indigenismo tradicional" basado en la "independencia entre lo étnico y lo nacional", la noción de "invariabilidad histórica" que lleva a asumir "lo étnico" desde un enfoque esencialista, y en la concepción de "anterioridad del fenómeno étnico" que niega sus vinculaciones e implicaciones en la estructura de clases que conforman nuestras sociedades nacionales actuales. Así como también se propaga la visión del Estado nacional-latinoamericano como la síntesis del "proyecto de los sectores dominantes" que busca la integración de las diferencias, el aniquilamiento de las pluralidades y la homogeneización de las diversidades sociales en favor del andamiaje del desarrollo capitalista.

En síntesis, el abordaje y tratamiento de "la cultura" en América Latina como objeto de estudio por parte de académicos e investigadores, responde -como toda la producción de conocimiento- a su

3 En este sentido, el trabajo realizado por un grupo de antropólogos en el diseño, desarrollo teórico-metodológico y puesta en práctica del proyecto de autonomía aplicado en la Costa Atlántica de Nicaragua para atender a poblaciones indígenas de esa región -miskitos, sumos, ramas y otros grupos- a partir de las iniciativas políticas del Gobierno de Reconstrucción Nacional y del Frente Sandinista de Liberación Nacional, constitu ye un importante avance en la discusión sobre la forma de abordaje de la temática (Rodríguez, 1991). 
contexto histórico, económico $\mathrm{y}$, sobre todo, político. Ello se comprueba desde la dependencia en relación con centros europeos y norteamericanos de principios del siglo XX, pasando por el énfasis de determinados paradigmas (evolucionismo, positivismo, etc.) propio del proceso modernizador impuesto en Latinoamérica, hasta el enfoque "eurocentrista" de la temática, que dieron un tratamiento prejuicioso, fragmentario, vacío de contenido y abstracto de la "cultura", así como un desconocimiento de las "identidades culturales" presentes en la región, bajo una visión homogeneizadora de la sociedad. A esta forma de abordaje coadyuvó el desarrollo de la antropología -dentro de la división sociotécnica del trabajo- como disciplina funcional a los mecanismos de dominación y control ejercidos desde los sectores hegemónicos.

Sin embargo, como la ciencia nunca es ajena a su contexto sociopolítico, los procesos de liberación y resistencia acaecidos en la región a partir de los 70, conjuntamente con la incorporación del paradigma marxista en la discusión académica, permitieron el replanteamiento y "desacralización" de las teorías y proposiciones elaboradas dentro de la antropología y sus diferentes vertientes disciplinarias.

Ya en el actual siglo XXI, estas revisiones, sumadas a los debates en torno a la división del conocimiento en disciplinas y especializaciones dentro de las ciencias sociales, permiten desmonopolizar la temática de la "cultura" de la antropología y caminar hacia un abordaje interdisciplinario o más bien "transdisciplinario" -como plantea García Canclini, e incluso incorporar el arte como una forma del conocimiento. A su vez, comienza a tomar mayor protagonismo el tema de las "identidades culturales" tanto en el nivel académico como en el nivel sociopolítico que, como vimos, son procesos interrelacionados. Ya no es posible ocultar, negar ni invisibilizar las diferencias culturales dentro de las sociedades nacionales, situación que para algunos autores constituye un lado positivo de la "globalización".

Desde esta visión critica y compleja que intenta superar el abordaje fragmentado de la realidad, se circunscribe el próximo apartado para procurar descubrir las incumbencias de la cultura y de la temática de las "identidades culturales" en la construcción de sociedades democráticas, participativas, plurales, inclusivas, que permitan la transformación del Estado a partir de una nueva ciudadanía.

\section{Las "identidades culturales" en la construcción de una nueva ciudadanía}

Los países latinoamericanos son actualmente el resultado de la sedimentación, yuxtaposición y entrecruzamiento de tradiciones indígenas (sobre todo en las áreas mesoamericana y andina), del hispanismo colonial católico, y las acciones políticas, educativas y comunicacionales moderna.

N. García Canclini.

\section{Comenzando por el enfoque teórico-conceptual}

En el presente apartado, se pretende analizar la relevancia y el rol que juegan y podrían jugar las "identidades culturales" en la construcción de una democracia verdaderamente participativa, que supone una ciudadanía plena y que requiere de nuevas 
instituciones - un nuevo Estado- en el actual contexto de la región. Para ello, en esta primera parte se presentarán algunos aportes teóricos respecto al tema, para luego analizar la potencialidad de dichas nociones en relación con el objetivo señalado.

En primer lugar, se considera necesario retomar los aportes sobre "cultura" desde la corriente marxista - como los de L. F. Bate, I. Vargas y M. Sanoja mencionados anteriormente-. Según dicho enfoque, la cultura posee una "existencia material y relaciones con las formas de conciencia que se expresan fenoménicamente". Pero también importa señalar que la cultura tiene un "carácter procesal que es resultado de la creación y recreación humanas". Ella refiere a procesos de creación social y de transmisión de dichas creaciones que se podrían sintetizar en la llamada "herencia cultural" (Vargas Arenas y Sanoja Obediente, 1993: 19-61). Los elementos que conforman dicha herencia cultural se concretan en expresiones formales de las acciones compartidas por los individuos dentro de una sociedad. Estas acciones son posibles mediante las interrelaciones sociales que requieren de formas de identificación que cohesionan a los individuos $\mathrm{y}$ hacen posible el logro de metas comunes. Las "acciones sociales" se dan en un marco de comunidad con el manejo de "claves" comunes que hacen que la identificación opere y que a su vez son posibles porque dicha "identificación" opera.

Cada marco histórico de acciones e identidades incorpora nuevos elementos que se sustentan en los anteriores. Por tanto, puede decirse que no existe "la" identidad cultural, sino una secuencia de identidades, que no son estáticas sino dinámicas. Entonces, si la cultura es expresión de la sociedad, la herencia cultural y las identidades culturales que ella supone no refieren solamente a elementos formales. Es decir, las identidades que establece un pueblo con su herencia cultural e histórica pueden convertirse en un instrumento para su defensa contra intentos de homogeneización cultural desde fuera.

Esta visión histórica de la cultura permite concebir al sujeto como agente social activo, con conciencia de los contenidos con los cuales se identifica, del papel que ha jugado y puede jugar para transformarlos en beneficio propio, e identificar y generar resistencia y rechazo hacia contenidos ajenos a su herencia cultural. Es una visión humanizadora de la cultura, del hombre y de la mujer.

En segundo lugar; importa destacar los aportes de M. García Alonso y C. Baeza Martín (1996), quienes presentan un "modelo teórico" que permite un nuevo enfoque sobre el tema de la "identidad cultural" y su relación con la construcción de nueva ciudadanía. Los modelos conceptuales tienen la propiedad de ser intermediarios, lo cual les da una gran potencialidad para descubrir y producir con acumulaciones y reajustes una nueva información. Por ello, la definición de "identidad cultural" no surge de una vez, resulta, como expresión simplificada del modelo y es una especie de resultado y punto de partida a la vez.

Desde este enfoque, el término "identidad" no sólo hace referencia a determinados objetos producidos por una cultura o forma de cultura, sino que incluye el resto 
de los elementos: "el alter $\mathbf{y}$ el sujeto con el que se comunica, la herencia cultural de este y la actividad de la cual los objetos son su resultado". La "identidad cultural" de un grupo social o de un sujeto de la cultura consiste en "la producción de respuestas y valores que como heredero y trasmisor, actor y autor de su cultura, éste realiza en un contexto histórico dado, como consecuencia del principio sociopsicológico de diferenciación-identificación en relación con otro grupo o sujeto culturalmente definido" (García y Baeza, 1996). La identidad es definida como un "proceso sociopsicológico de comunicación cultural". Por tanto, interesa no sólo la "mismidad" sino la "otredad". O sea no sólo lo distintivo de una cultura, sino el tipo de relación que ha tenido, tiene o establece con otra cultura. La "identidad cultural" constituye un "concepto relacional" y refiere a un proceso que tiene lugar en distintos niveles: identidad de grupo primario, de una nación, de una región supranacional, etc.

El carácter sociopsicológico de los procesos identitarios implica la inclusión del papel de lo "microideológico" en cualquiera de los niveles de análisis. Pero desde este enfoque lo ideológico no es derivación automática de la posición económica de los sujetos sociales. Esta conceptualización permite visualizar con mayor intensidad y potencia teórica "lo particular" de las realidades socioculturales. Se realiza una ampliación de lo ideológico hacia expresiones de cuerpos menos estructuradas y más cercanas a actitudes no racionalizadas, como aquellas ligadas a la vida cotidiana de los grupos sociales. La identidad (o identidades) se explican a partir de sus expresiones en la vida cotidiana de la población. La "identidad cultural" constituiría así una variable explicada en función de un conjunto de variables como el tiempo o momento histórico, espacio geográfico, estructura socioclasista, raza y etnicidad, migraciones y género, que cambia en sus expresiones concretas (lengua$\mathrm{je}$, instituciones sociales, indiosincrasia, cultura popular, relaciones familiares, arte y literatura).

En este estudio, se enfatiza sobre todo la importancia de la dimensión psicosocial en la interpretación de los fenómenos macrosociales y la dialéctica de lo micro y macro. Es importante señalar, además, que este concepto de "identidad cultural" deja ver el derecho a la existencia, coexistencia y desarrollo de distintas formas de cultura, o sea, de grupos humanos que asumiendo sus proyectos de vida, actúan generando respuestas y valores que retroalimentan su cultura. Es un concepto que permite traer a la conciencia la necesidad de transformar el tipo de relación vertical (es decir de superioridad-inferioridad, dominacióndependencia) propio del capitalismo y desbloquear la homogeneidad concebida como unitaria, otorgándole así "legitimidad" a formas de cultura diversas en una sociedad. Se busca, además, diferenciar la "identidad cultural", tal y como es sentida por el pueblo, de la identidad establecida por las clases y grupos dominantes.

También, distinguen procesos culturales de procesos identitarios, ya que los primeros se abordan desde la mismidad del sujeto de la cultura, su actividad y sus productos materiales y espirituales, mientras que los segundos se abordan desde 
la perspectiva de la comunicación de un "sujeto de la cultura" con otros "sujetos de la cultura" para él significativos, bajo la perspectiva de la alteridad.

\section{Desafíos de las "identidades culturales" en el actual contexto latinoamericano}

En primer lugar, es necesario señalar que el tema de "la" identidad ha sido objeto de numerosas y variadas reflexiones en América Latina. Fue una meta y un sueño para nuestros próceres durante el siglo XIX en su intento por defender "lo propio" frente a influencias extranjeras (Simón Bolívar, José de San Martín, José Martí, José Artigas, etc.). Pero además fue utilizada desde una postura crítica como arma ideológica frente a modelos culturales hegemónicos por parte de políticos y ensayistas de principios del XX (José E. Rodó, José C. Mariátegui, etc.), entre los cuales se manifestaba, incluso, el deseo de conformar una raza única: la "raza cósmica" (José Vasconcelos). Se trata de una búsqueda que continúa incluso hasta nuestros días, a través de profundos estudios y análisis por parte de filósofos y escritores contemporáneos ${ }^{4}$.

Si bien el interés -en extremo necesariopor parte de muchos de estos pensadores, políticos y ensayistas ha sido la independencia, la autonomía política y económica del continente y la resistencia frente a "lo otro" en su carácter violento y avasallante, es importante cuestionar si en realidad existe "una" identidad latinoamericana. Es sabido que en el mismo continente

4 Cabe mencionar a Leopoldo Zea, Arturo Ardao, Miguel Rojas Mix, Enrique Dussel y Eduardo Galeano, entre otros. coexisten múltiples "identidades culturales", las cuales se crean a partir de herencias variadas, tras procesos de "transculturación" donde convergen valores "externos" (europeos) y valores de nuestros pueblos y comunidades indígenas y negras ${ }^{5}$. Es importante establecer que el término "transculturación", elaborado por el antropólogo cubano F. Ortiz, refiere al proceso que ocurre cuando dos o más culturas comparten y mezclan sus culturas, cuando hay interacción entre dos culturas, pero una de las dos pierde más que la otra. Esto ocurre involuntariamente y generalmente por la fuerza. No consiste solamente en adquirir una cultura distinta ("aculturación"), sino que implica la pérdida o desarraigo de una cultura precedente.

Por otra parte, si bien la relación con el "otro" (sea este un país o bloque de países que buscan homogeneizar y universalizar desde la imposición de su cultura, o sea simplemente cualquier "otra" región o país) ha producido en América Latina la necesidad de presentarse frente a sí misma y frente al mundo como "región", no debe perderse de vista que existen en la misma zona procesos de "diferenciación -identificación" que dan lugar a "identidades culturales" muy variadas entre sí, según el contexto histórico y geográfico en que se producen y las características sociodemográficas de su población.

En segundo lugar, es necesario tomar en cuenta que al interior de cada país, los procesos políticos y económicos de la

5 Según G. Bonfil Batalla (1977), a partir de la dominación colonial, la población latinoamericana con diferencia proporcional en cada país tuvo tres troncos originales básicos: 1) el indoamericano, 2) el africano y 3) el europeo. 
modernización europea tuvieron gran incidencia en la conformación de los Estados Nacionales $^{6}$ de finales del siglo XIX y principios del XX y en el surgimiento de las "sociedades nacionales" en América Latina.

A partir de la expansión del proyecto modernizador europeo, las élites criollas en procura de construir "la nación" desarrollaron una estructura política, económica y social que se caracterizó por desconocer al "otro": la gran mayoría de la población (zambos, negros, indios, mulatos, mestizos, etc.). Se trató de un proceso de criollización y mestizaje que supuso hostigamiento, persecución y hasta exterminio de comunidades indígenas enteras -tal fue el caso del etnocidio en Uruguay-, así como la explotación y exclusión de la vida social y política de los negros, traídos como esclavos desde distintas partes de África. Se buscó afanosamente la "integración nacional" a partir del desconocimiento e invisibilidad de la pluralidad sociocultural.

Los estados latinoamericanos, -que en general fueron creados mucho antes que las naciones por incidencia de países hegemónicos y de sus intereses económicos en la región- necesitaron inventar "la nación", para lo cual se lleva a cabo una serie de mecanismos de "homogeneización

6 Tal como refiere H. Díaz Polanco, en el origen del Estado Nacional operaron varias "fuerzas": a) El racionalismo, sistema de pensamiento que convirtió el Estado en un agente al servicio del "ciudadano" y no sólo del monarca, que impulsó los sistemas uniformes de derecho y la noción de "igualdad legal". b) El capitalismo que transforma las relaciones económicas y sociales dando lugar al trabajador libre, creando la estructura social de clases. c) El Estado que articula sistemas educativos, legales y organiza las burocracias capaces de racionalizar el funcionamiento de las nuevas estructuras sociopolíticas soberanas (Díaz Polanco, 1989. cultural" por medio del lenguaje y la comunicación. En procura de este objetivo, se puede comprender la narración de la "historia nacional" que difunde valores con los cuales los sujetos se identifican posibilitando así la pertenencia a esa sociedad "nacional". Este proceso incluye tanto lo formal: el orden jurídico y las diferentes instituciones (Estado, escuela, familia. Iglesia, etc.), como lo informal: la vida cotidiana, la recreación y los pasatiempos donde se aprende y asimila el mundo simbólico que refuerza la conciencia "nacional".

Lo cierto es que ante la ausencia de una diversidad nacional que fuera capaz de establecer como opción la creación de una soberanía aparte, el Estado liberal latinoamericano, cooptado por la "nacionalidad dominante criollo-mestiza", despliega junto con el proyecto capitalista, una homogeneización cultural fanática. A diferencia de lo que ocurrió en Europa, no existían nacionalidades con capacidad de organización política, sino una gran variedad de comunidades desarticuladas y sin perspectiva nacional (grupos étnicos).

En definitiva, desde la conquista pasando por los procesos emancipatorios y la conformación de los Estados Nacionales hasta la actualidad -más allá de los discursos y reconocimientos jurídicos desde el Estado y desde organizaciones internacionales-, los grupos étnicos (indios y negros) latinoamericanos han luchado por resistir frente al avasallamiento, persecución, explotación, desconocimiento e invisibilidad, ya fuera por parte de monarquías europeas, élites criollas o la actual "sociedad nacional" y también "globalizada". 
En el actual contexto de "globalización" existe, paralelamente a una tendencia a la homogenización, alienación cultural y pretendida "integración universal", una tendencia cada vez mayor a reconocer y afirmar las particularidades y diversidades culturales dentro de las sociedades nacionales. Así como también existe un fuerte cuestionamiento hacia los Estados Nacionales dadas las transformaciones que ha generado la mundialización de los mercados y la crisis de legitimidad tras las reformas neoliberales de los 90 y los procesos de corrupción en la región.

La diversidad incluso ya no refiere solamente a aspectos étnicos, sino que involucra otros muy variados: desde geográficos hasta condiciones como edad, sexo, ocupación, lugar de residencia (sobre todo el fenómeno migratorio), lo cual propicia la aparición de elementos muy variados que intervienen en el proceso de diferenciación-identificación: modos de hablar, formas de conducta, valores, símbolos, creencias, expresiones artísticas, etc.

Si bien ello constituye un campo fértil para la "aceptación" de la pluralidad y multiculturalidad en las sociedades, paradójicamente podría convertirse en obstáculo para la búsqueda de la transformación del orden existente. Es decir, los problemas y reivindicaciones de los grupos étnicos se relativizan en un mar de asociaciones, grupos, organizaciones de la sociedad civil; o son corrompidos y etiquetados como un fenómeno más de la "globalización". A su vez, los grupos étnicos terminan por atrincherarse en la defensa de sus legítimos derechos, sin posibilidad de incidencia frente al resto de la sociedad. Las sociedades nacionales terminan por "aceptar" y "respetar" sus diferencias pero no se cuestionan a sí mismas desde "lo diferente", desde el "otro", impidiendo así alcanzar nuevas sociedades y Estados plurales.

América Latina presenta cuarenta millones de habitantes indios que pertenecen a más de 400 etnias, con diferencias regionales en cada país y donde persiste la pobreza, la exclusión y la desigualdad más escandalosa del planeta. Por ello, los problemas culturales deben colocarse en el centro mismo del debate y de la construcción de una nueva ciudadanía. Las "etnias" son sistemas sociales permanentes de larga duración histórica. Etnia es sinónimo de pueblo diferente a la "sociedad nacional" porque no tiene necesariamente un Estado propio. El pueblo o etnia más grande es el quechua (ubicado territorialmente en cuatro países), pero también se encuentran el náhuatl, el aymara, el quiché y el maya, entre los más importantes numéricamente.

Las dificultades para comprender las diferencias étnicas en forma compleja, parecen presentes también en el mundo académico así como en organismos internacionales (UNESCO), donde se legitima cada vez más como punto de llegada y no como punto de partida, la noción de "multiculturalidad". Es decir, se considera -desde este trabajo- que debería hablarse sobre todo de "interculturalidad" en tanto permite colocar en el centro de atención la necesidad de un diálogo liberador. ¿Pero es posible este diálogo dentro de una sociedad capitalista o será imprescindible un cambio de modelo de sociedad? ¿Ambas realidades (diálogo intercultural y cambio 
de modelo de sociedad) se darían en forma interrelacionada o la una está condicionada a la otra?

Y hasta se constata el desconocimiento de las comunidades étnicas en los estudios estadísticos realizados hasta el momento: son imprecisos y escasos. La demografía latinoamericana tiene una tarea pendiente: el diseño y aplicación de instrumentos estadísticos adecuados para dar cuenta real de la composición étnica de cada país. Así como también serían necesarias mayores investigaciones y estudios sobre las comunidades negras en varios países, como por ejemplo en Uruguay.

Por esto, resulta fundamental como propone Bonfil Batalla (1997): "desmontar el andamiaje ideológico, sustento de la visión cultural del sector dominante en nuestras sociedades, resulta una tarea prioritaria para sanear el ambiente intelectual, construir una visión más auténtica de nosotros mismos y conducir el debate sobre nuestro futuro a partir de concepciones más próximas a la realidad". Es necesario superar la "colonización intelectual" que ha influido en la imagen colectiva de nuestras realidades nacionales, en la visión del pasado, la percepción del presente y la imaginación del futuro. La manipulación de la diferencia cultural por parte del poder ha sido un obstáculo para construir una democracia que incluya a todos los individuos, grupos y pueblos presentes en nuestras sociedades, en tanto ha impedido formular un proyecto nacional inclusivo, al ignorar, despreciar o anular las potencialidades creativas de la población. Pero además, con la globalización cultural las sociedades ven desdibujarse su perfil cultural, mientras las "identidades culturales" viven la paradoja de ser al mismo tiempo expuestas como artículo de consumo turístico, profundamente ignoradas.

En América Latina, la "globalización" ha profundizado las desigualdades, la exclusión social, política y cultural de vastos sectores de la población. Se ha puesto en juego cuál es el modelo de sociedad que queremos construir. El rescate y defensa de las "identidades culturales" significa plantearnos hacia dónde queremos llegar. "Seremos a partir de lo que somos" (Bonfil Batalla, 1997). Esto implica dar prioridad a ciertos valores que permitan defender nuestros recursos naturales, nuestro patrimonio cultural, nuestra riqueza. Para lo cual la sociedad requiere un equilibrado "control cultural", es decir, la capacidad social de decisión sobre sus recursos culturales: los componentes de una cultura que deben ponerse en juego para identificar las necesidades, los problemas y las aspiraciones de la propia sociedad, e intentar satisfacerlas, resolverlas y cumplirlas. En este sentido, la dimensión cultural debería adquirir un mayor protagonismo en todos los procesos de integración regional existentes en Latinoamérica.

El rescate y la afirmación de las "identidades culturales" implica tomar decisiones hacia el futuro, pero ellas deberán ser colectivas. Dentro de estas decisiones se podría ubicar la de construir un Estado diferente, plural, fuerte, con representatividad y capacidad de movilización.

Sabido es que la globalización cultural incide en la progresiva mutación de los "ciudadanos" en meros "consumidores", 
despolitizando así a los sujetos, acallando sus demandas, adormeciendo su capacidad crítica, a partir de la manipulación mediática (desde noticieros hasta telenovelas y películas, en el medio más masivo en América Latina: la televisión).

Los cambios se darán desde una profunda transformación cultural que permita recrear la política para la formulación de un nuevo proyecto civilizatorio. En este sentido, es interesante la propuesta de G. Bonfil Batalla (1997) sobre "etnodesarrollo", en tanto supone un cambio de la correlación de fuerzas sociales, un cambio político que incline la balanza -hoy favorable a los intereses que impulsan los procesos de imposición y enajenación cultural-a favor de los grupos sociales que pugnan por el desarrollo de su cultura propia (etnias, regiones, localidades).

Esto requiere como condición el reconocimiento jurídico y político de los diversos grupos étnicos como unidades políticas, aunque ello no es suficiente. Como tampoco la ejecución de políticas asistencialistas, positivamente discriminatorias hacia estos grupos (educación, salud, etc.) por parte del Estado. Dichas políticas no alcanzan, pues en la realidad no existen "activos y oportunidades" en una estructura social desigual. Por otra parte, son los propios grupos étnicos quienes deben decidir sobre sí mismos y adquirir el lugar al que tienen derecho en la sociedad. En este sentido, los patrones simbólico-culturales adquieren gran relevancia, ya que intervienen en la capacidad de estos grupos para apropiarse de espacios políticos, tomar decisiones, pertenecer a una sociedad plural. Sin verdadera participación ciudadana de estos grupos, no es posible construir sociedades inclusivas, ni democráticas, lo cual implica capacidad de organización, autogestión, preservación de su hábitat, uso y reconocimiento de su propio idioma.

La ciudadanía es una noción y una realidad que nace con "la modernidad", pero que ha ido evolucionando a lo largo de la historia a partir de reivindicaciones y luchas por parte de los sectores populares organizados. Así se fueron reconociendo derechos políticos, civiles y sociales. La ciudadanía implica pertenencia a una comunidad, relaciones sociales, derechos reconocidos y ejercidos. De allí la importancia de los procesos sociopsicológicos que permitan transformar los patrones simbólicos-culturales heredados de una relación vertical y de dominación.

En resumen, desde los aportes presentados es posible comprender la existencia material e ideológica de la "cultura". Ella se crea a partir de "acciones" que surgen desde las relaciones sociales en el marco de una comunidad, en la cual, gracias al proceso de "identificación", operan determinadas "claves comunes" que crean y recrean "identidades" a la vez que otorgan cohesión y permiten el alcance de metas y proyectos en común. Las "identidades" que establece un pueblo con su herencia cultural e histórica pueden convertirse en un instrumento de resistencia frente a la "homogenización cultural" impuesta directa o subliminalmente desde fuera. Desde esta visión histórica y humanizadora de la cultura, el sujeto es concebido como "agente social activo".

La creación de "identidades culturales" tanto en el sujeto, grupos, naciones $\mathrm{y}$ 
regiones, implica lo social pero también lo psicológico. Dentro de este proceso sociopsicológico "donde también entran en juego las ideas políticas" adquiere gran importancia la relación con "el otro", la alteridad. Desde este enfoque, lo particular y lo microideológico cobran protagonismo. La ideología comprende desde actitudes racionalizadas y estructuradas hasta otras más cercanas a la vida cotidiana.

Desde este marco teórico, las "identidades culturales" adquieren mayor potencialidad a la hora de analizar las posibilidades de los sujetos en la conformación de nueva ciudadanía, desde la ruptura de relaciones verticales (dominación-dependencia, superioridad-inferioridad) presentes aún hoy en las sociedades nacionales latinoamericanas. Pero, además, promueve el derecho a la existencia, coexistencia y desarrollo de distintas formas de cultura al desbloquear la "homogeneidad cultural" y diferenciar la "identidad cultural" sentida por el pueblo de la establecida por las clases y grupos dominantes. El problema de la "identidad" en América Latina ha sido objeto de numerosos ensayos, investigaciones y discusiones que han pretendido unificar a los pueblos, defender los recursos e intereses propios ante "el otro" que casi siempre se ha manifestado como violento y avasallador, universal, alienante y homogeneizador.

No obstante, el compartido interés por defender "lo propio" (aunque en materia cultural ello siempre será un tema discutible, en tanto somos producto de constantes procesos de transculturación desde la época de la conquista), esta necesidad por presentarnos como "región" puede llegar a desconocer la diversidad cultural al interior del continente, de los países, de las ciudades.

La acción homogeneizadora de los Estados Nacionales en América Latina ha negado a vastos sectores de la sociedad (sobre todo etnias indígenas y negras) al excluirlos sutil o directamente de sus estructuras políticas, económicas, sociales y culturales. En la actualidad, si bien la globalización ha modificado el escenario de los Estados Nacionales al cuestionar su matriz sociopolítica y ha "legitimado" las diferencias, se generan nuevos procesos de exclusión. Baste mencionar la "brecha digital" en América Latina, por lo cual "pobres" y "no pobres" acceden en forma desigual a los avances de la tecnología informática, profundizada por la adscripción étnica y el lugar de residencia. El desafío desde el ámbito académico consiste en romper con la "colonización intelectual" y promover desde un abordaje complejo de la realidad el diálogo entre las distintas culturas en América Latina, lo cual implica (y quizás supone) la transformación de la sociedad actual bajo el modelo neoliberal y excluyente.

\section{Reflexiones y comentarios finales}

En esta última parte del estudio, se presentarán algunas reflexiones que no pretenden ser conclusivas ni determinantes sino, por el contrario, colocar en el debate algunas líneas o tendencias de investigación sobre el tema.

En primer lugar, importa mencionar que la propia categoría de "cultura" o la dimensión cultural ha adquirido en los últimos tiempos un extraordinario auge. No sólo 
se percibe tanto en la sociedad actual sino también -y en forma cada vez más interrelacionada- en el mundo académico. Quizás dentro de este ámbito, el fenómeno responde a la revisión que viene produciéndose al interior de las ciencias sociales y la búsqueda por superar el divorcio histórico entre "filosofía" y "ciencia". A dicha superación parecen cooperar los llamados "estudios de la complejidad" y los "estudios culturales" (Wallerstein, I, 2001). En el nivel societario, el auge de la cultura parecería estar relacionado con una progresiva e indetenible crisis de un modelo civilizatorio basado en la búsqueda afanosa por la ganancia y en la razón instrumental. Una crisis y un declive que surgen justamente en la fecha en que emerge la denominada "globalización".

En segundo lugar, si bien en este contexto de globalización las sociedades nacionales y las identidades construidas en relación con ellas parecen en profunda revisión, aún permiten analizar y explicar situaciones de exclusión y discriminación del pasado que perduran en nuestra América Latina. Es cierto que también se producen nuevos procesos de identificación a partir del fenómeno migratorio desde nuestros países hacia los Estados Unidos y Europa, así como de la influencia de los medios masivos de comunicación (que incluyen desde la televisión hasta la Internet). Lo cierto es que con la "globalización" también se generan procesos de homogeneización y exclusión social.

En tercer lugar, los nuevos movimientos sociales (étnicos, campesinos, etc.) surgidos en América Latina constituyen un síntoma de la necesidad de resignificar la noción y la realidad de la ciudadanía (originariamente ligada al fenómeno urbano). Ellos cuestionan incluso el orden existente desde la modernización, es decir, el proyecto civilizatorio. Por ello, sería necesario ahondar en las nuevas incumbencias histórico- políticas de la cultura en relación con la construcción de una "ciudadanía democrática".

\section{Bibliografía}

Acosta, Yamandú (2005). Sujeto v democratización en el contexto de la qlobalización. Perspectivas críticas desde América Latina. Montevideo: Facultad de Humanidades y C. de la Educación. Editorial Nordam Comunidad.

Bonfil Batalla, Guillermo (1997). Pensar nuestra cultura. México: Alianza Editorial.

Caetano, Gerardo y otros (1992). Identidad uruguaya: ¿mito, crisis o afirmación? Montevideo: Trilce.

Coutinho, Carlos N. (1997). Notas sobre ciudadania e modernidade. Praia Vermelha, 1, 1.

Díaz Polanco, H. (1989). Formación nacional y cuestión étnica. México: Colección de Antropología Americana. Instituto Panamericano de Geografía e Historia.

García Alonso, Maritza y Baeza Martín, Cristina (1996). Modelo teórico para la identidad cultural. La Habana: Centro de Investigación y Desarrollo de la Cultura Cubana Juan Marinello.

García Canclini, Néstor (1995). Consumidores y ciudadanos. México: Editorial Grijalbo. 
Giddens, Anthony y Hutton, Will (eds.) (2001). En el límite, la vida en el capitalismo global. Barcelona: Tusquets.

Rodríguez, Omar (1991). Etnias, imperios y antropología. Caracas: Universidad Central de Venezuela. Facultad de Ciencias Económicas y Sociales.

Rojas Mix, Miguel (1991). Los cien nombres de América. Eso que descubrió Colón. Colección Identidad Cultural. San José: Editorial de la Universidad de Costa Rica.
Schwartz, Jorge. Negrismo y negritud (1993). En: Historia v cultura en la conciencia brasilera. Leopoldo Zea (compilador). Tierra firme.

Vargas Arenas, Iraida y Sanoja Obediente, Mario (1993). Fundamentos conceptuales y políticos. En: Historia, Identidad y Poder. Caracas: Fondo Editorial Tropykos.

Wallerstein, Immanuel (2001). Conocer el mundo, saber el mundo: el fin de lo aprendido. Una ciencia social para el siglo XXI. México: Siglo XXI. 


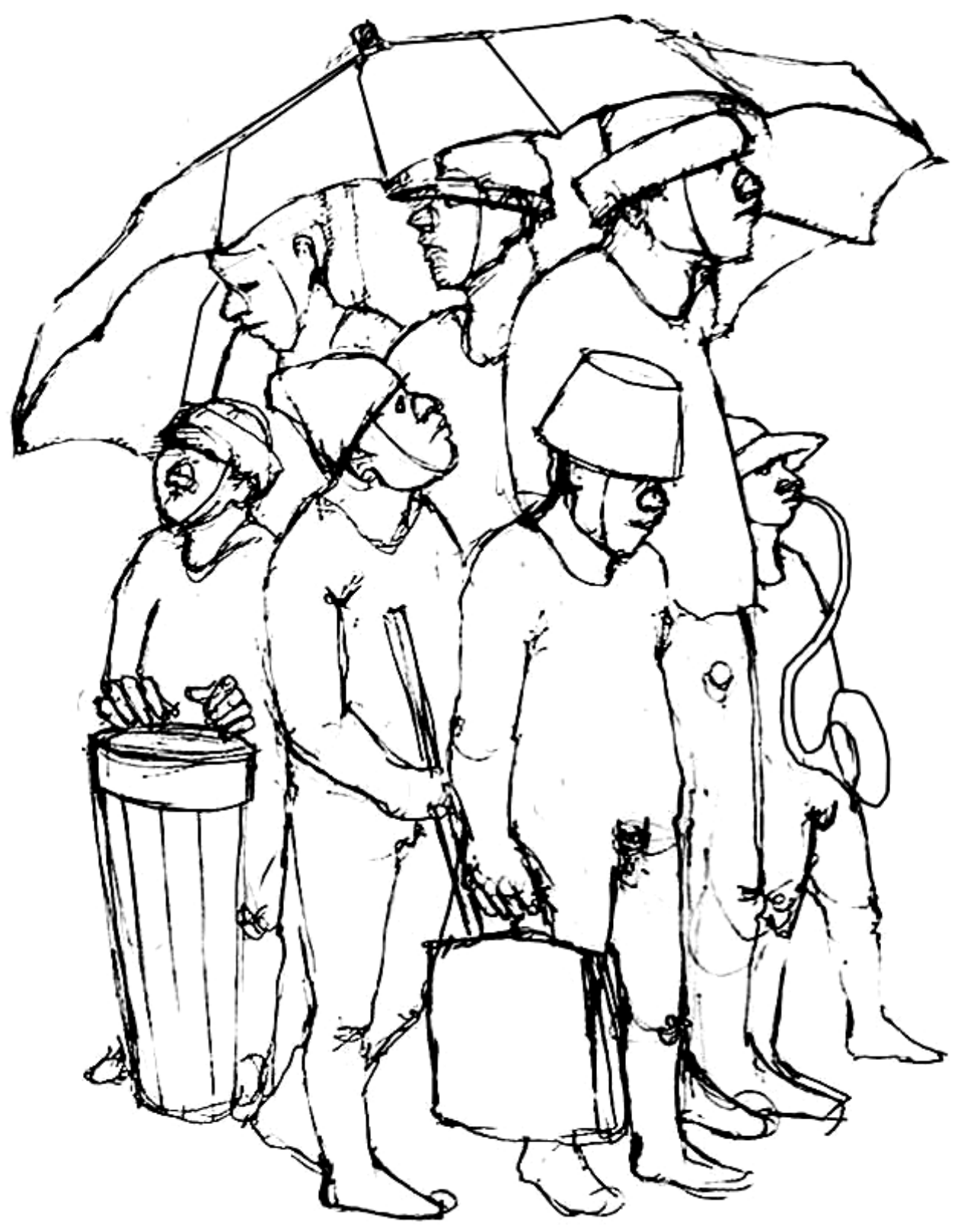

Jorge Crespo Berdecio Utopía 6

Tinta sobre papel 2017 